\title{
InfiscLab: Laboratório de Inovação Corporativo voltado para o Setor Público Municipal
}

\author{
Évelinc Luizi Huppes ${ }^{1}$, Lucas Boes Baptista ${ }^{1}$, Nicolas Rodrigo Huppes Carvalho ${ }^{1}$, \\ Fernando Lehnen ${ }^{1}$, Morecy Vaz Móre ${ }^{1}$, Juliano Schorr ${ }^{1}$, Francisco Assis Moreira \\ do Nascimento ${ }^{1}$ \\ ${ }^{1}$ Infisc - Inteligência em Tecnologia Ltda \\ Rua Júlio de Castilhos, 2579/507 - Taquara - RS - Brazil \\ \{evelinc,lucas,nicolas,fernando,morecy,juliano,francisco\}@infisc.com.br
}

\begin{abstract}
This work presents InfiscLab, a corporate innovation laboratory focused on the public sector, specifically on the municipal tax sector. The laboratory is in operation, working in a non-presential way, in carrying out innovative projects for the municipalities. A case study is reported on a project aimed at creating a solution to charging ITBI in municipalities, which illustrates the relevance of the approach to addressing crucial problems in the public sector.
\end{abstract}

Resumo. Este trabalho apresenta o InfiscLab, um laboratório corporativo de inovação voltado para o setor público, mais especificamente para a área fazendária e tributária municipal. O laboratório se encontra em operação, atuando neste momento de forma não-presencial, na realização de projetos inovadores para as municipalidades. Um caso de estudo é reportado sobre um projeto voltado para criação de uma solução para o problema da cobrança do ITBI nos municípios, que ilustra a relevância da abordagem para o tratamento de problemas cruciais no setor público.

\section{Introdução}

A Infisc é voltada à atuação na área de tecnologia e inteligência fiscal com finalidade de oferecer ferramentas e consultoria para as áreas fazendárias municipais. Um dos produtos pioneiros da Infisc é o Sistema-Infisc, sistema de gestão e inteligência fiscal [Nascimento 2009], que permitiu a operacionalização, acessível aos pequenos e médios municípios, da Nota Fiscal de Serviços eletrônica (NFSe), provocando o aumento de receitas próprias e a atração de novas empresas.

Ao longo de sua atuação junto ao setor público, a Infisc vem constatando, na área fazendária pública municipal, a falta de ação no sentido de busca de inovações em métodos e trabalhos, que simplifiquem e melhorem os serviços oferecidos por este setor. Algumas das experiências da Infisc foram reportadas em [Nascimento 2009], onde são apresentados os resultados obtidos com o uso do Sistema-Infisc em um município do estado do Rio Grande do Sul e que demonstram a importância da inovação na melhoria dos serviços do setor público.

Em [Sano 2020], é apresentado um mapeamento dos laboratórios de inovação e a contribuição deles para a organização, melhoria, racionalização de entes públicos e privados, assim como para a produtiva e eficiente interação interna e externa entre todos os envolvidos e interessados (de stakeholders, termo em inglês que melhor resume este conceito). 
A partir deste mapeamento apresentado em [Sano 2020] e outros estudos sobre inovação no setor público do Brasil [Cavalcante 2017], percebeu-se que finalmente estava sendo dada a devida atenção à questão da inovação no setor público, há tanto tempo já ressaltada pela Infisc [Nascimento 2009]. Foi então, justamente se baseando nestas iniciativas mapeadas, que a Infisc resolveu se engajar a esta movimentação e implementar o InfiscLab, o Laboratório de Inovação Corporativo da Infisc que será apresentado neste trabalho.

A experiência da equipe da Infisc com o setor público municipal tem constatado que os procedimentos na tributação do ITBI (Imposto sobre a Transmissão "inter vivos", a qualquer título, por ato oneroso, de Bens Imóveis, por natureza ou acessão física, e de direitos reais sobre imóveis) são realmente complexos e realizados de forma não digital, na quase totalidade dos municípios brasileiros. Baseado neste conhecimento acumulado sobre ITBI, a equipe da Infisc tem investigado como tornar todo o processo digital e assim facilitar o trabalho de todos os agentes envolvidos no processo (comprador, vendedor, intermediador, consultores, advogados, agentes do ente público tributante). Nesse contexto, ao planejar a criação do InfiscLab, foi decidido adotar como estudo de caso prático inicial o desenvolvimento de um processo de digitalização das tarefas vinculadas à tributação do ITBI.

Vale destacar que a finalidade do presente artigo é mostrar como se preparou e organizou o InfiscLab, já apresentando os primeiros passos e estudos realizados no primeiro estudo de caso (digitalização do processo de cobrança do ITBI). Mas, sem a intenção de mostrar concluído o trabalho, uma vez que ainda está em andamento a consulta aos agentes interessados e o estudo para descrição de todos os fluxos e procedimentos.

O artigo está organizado como segue. Inicialmente, serão introduzidos alguns conceitos importantes relacionados com inovação e laboratórios de inovação e trabalhos similares ao proposto com o InfiscLab. Na Seção 2, serão descritas as cinco dimensões que nortearam a criação do InfiscLab: Estratégia, Serviços, Estrutura, Aprendizagem e Comunicação, segundo metodologia proposta no iLabthon [Conexão Inovação Pública RJ 2021], primeira maratona online sobre laboratórios de inovação do setor público, em que o InfiscLab participou e se classificou entre os dez finalistas, dentre 259 inscritos no evento. Na Seção 3, como validação do projeto de instalação do InfiscLab, é apresentado um estudo de caso, que se constitui no primeiro projeto posto em prática a partir da instalação do laboratório. Com a Seção 4, o artigo é concluído com algumas considerações sobre as experiências tidas até o momento no âmbito do InfiscLab.

\section{Laboratórios de Inovação}

Laboratório de inovação é, essencialmente, um espaço de colaboração e criação. Nele, ideias são trocadas, conhecimentos são compartilhados e projetos inovadores são desenvolvidos.

De acordo com [OCDE 2018], "Uma inovação é um produto ou processo (ou sua combinação) novo ou melhorado que se difere significativamente dos produtos ou processos prévios da unidade e que foi disponibilizado para usuários em potencial (produto) ou usado pela unidade (processo)."

O InfiscLab está voltado para identificar situações implementadas e também situações identificadas que se apresentem como passíveis de implementação nova ou de 
elaboração modificativa capaz de trazer uma nova, diferente e inovadora solução que possa simplificar ou melhorar o desempenho da área fazendária municipal, sem descuidar eventuais colaborações que possam ascender a outras áreas do município.

Neste trabalho, adota-se a definição dada em [Sono 2020]: "Laboratórios de inovação no setor público são ambientes colaborativos que buscam fomentar a criatividade, a experimentação e a inovação, por meio da adoção de metodologias ativas e da cocriação, na resolução de problemas”.

O importante para o InfiscLab é produzir resultados efetivos a partir da atividade experimental com avaliação de resultados daí obtidos, que se transformem em solução das deficiências, inconsistências e dos elementos inexistentes ou falhos. Com este foco, o InfiscLab resulta em eficiência e eficácia nas mudanças e melhorias implementadas nas ações fazendárias municipais, com vista à implementação de um processo arrecadatório tributário, que promova a valorização do bom contribuinte com plena justiça fiscal.

\section{Trabalhos Correlatos}

Longe de se apresentar aqui uma lista exaustiva dos vários laboratórios de inovação, que estão surgindo atualmente, são descritos apenas alguns exemplos notórios, por serem pioneiros ou por estarem se destacando em suas atividades mais recentemente. Por exemplo, GNova é o laboratório de inovação em governo, criado em 2016 pela Escola Nacional de Administração Pública [Sano 2020], voltado para o desenvolvimento de soluções inovadoras no âmbito do governo federal. Como a grande maioria dos laboratórios de inovação para o setor público, o GNova também adota metodologias ágeis [LeMay 2019] e o foco nas pessoas para promover a inovação na administração pública [Sano 2020]. Diferente do GNova, o InfiscLab nasceu dentro de uma empresa, que presta serviços para o setor público, mas adota estratégias similares no desenvolvimento de inovações se aproveitando de experiências práticas que tem realizado nos últimos 15 anos, conforme já reportado em [Nascimento 2009].

Vale destacar também o Laboratório de Inovação e Coparticipação do Tribunal de Contas da União (coLAB-i), que foi criado em 2015 com foco inicialmente "em trazer ferramentas e abordagens para empoderar os servidores e colaboradores do TCU a criar soluções inovadoras" [TCU 2021]. De acordo com a nomenclatura do laboratório britânico de inovação (NESTA), o coLAB-i se caracteriza como um espaço de talentos (capacitação dos servidores do TCU nas metodologias e ferramentas ágeis [LeMay 2019]) e de criação (de soluções inovadoras se fazendo uso das novas habilidades dos servidores). No caso do InfiscLab, que já contava com uma equipe com experiência de quase dez anos no uso de metodologias ágeis, como o Scrum [Sutherland 2016] utilizado pelo time de desenvolvimento de software, o foco desde o início já foi maior nos clientes da Infisc.

Assim como o InfiscLab, o NauLab, primeiro laboratório de inovação do setor público de Blumenau/SC [NauLab 2021], também foi criado a partir da participação no iLabthon [Conexão Inovação Pública RJ 2021]. No entanto a formação da equipe do NauLab, é diferente do InfiscLab, que tem sua origem no setor privado, já o NauLab é composto por oito pessoas, sendo $65 \%$ da equipe composta por servidores efetivos.

O laboratório tem como objetivo testar novas abordagens na solução de problemas complexos que se apresentam no dia a da gestão pública municipal de Blumenau/SC. O 
InfiscLab, que também oferece soluções para a gestão pública municipal, diferencia-se por atuar no setor privado, fornecendo soluções para entes públicos municipais.

\section{InfiscLab: Laboratório de Inovação Corporativo para o Setor Público}

A criação do InfiscLab se consolidou com a participação no evento iLabthon [Conexão Inovação Pública RJ 2021], primeira maratona online internacional para projeto de laboratórios de inovação. Neste evento, um laboratório deveria ser modelado de acordo com cinco dimensões específicas: i) Estratégia, que incluía justificativa, propósito, público-alvo, problemas a serem abordados, objetivos e escopo e área de atuação do laboratório; ii) Serviços, que deveria descrever os serviços oferecidos e necessidades atendidas pelo laboratório, além das abordagens para a criação dos serviços e como eles seriam acessados pelo público-alvo; iii) Estrutura, que deveria estabelecer a posição organizacional, a governança, os parceiros internos e externos, a estrutura física e/ou virtual e os recursos do laboratório; iv) Aprendizagem, que deveria apresentar as competências a serem desenvolvidas, incluindo os métodos, abordagens, técnicas e tecnologias, bem como, como de que forma aconteceria este aprendizado e como seria realizada a gestão do conhecimento no laboratório; e, v) Comunicação, que deveria mostrar os objetivos, o público-alvo, os conteúdos e os canais de comunicação focados pelo laboratório.

\subsection{Estratégia}

A criação do InfiscLab se justifica pela importância da disseminação da cultura da inovação e da dinâmica da transformação digital, tanto na empresa, como em todos os seus clientes. Sua implantação possibilita a prática da análise e solução de problemas específicos tratados com o uso de metodologias ágeis e ferramentas colaborativas, envolvendo servidores fazendários municipais e demais partes interessadas (contribuintes e outros colaboradores institucionais) no processo, desde o seu início, promovendo a aceleração no desenvolvimento de soluções inovadoras.

O objetivo do InfiscLab é se constituir como um canal aberto a novas ideias, bem como impulsionar parcerias e fomentar a captação de recursos. $\mathrm{O}$ foco de atuação do InfiscLab é o desenvolvimento de soluções (produtos, metodologias e serviços) voltadas para a transformação digital das áreas fazendária e tributária dos municípios brasileiros.

Os principais problemas a serem abordados, considerando os diversos cenários e realidades distintas dos municípios brasileiros, são: i) falhas na comunicação entre o órgão municipal e cidadão (contribuinte); ii) falta de capacitação técnica dos servidores ou de obtenção de informações (legislativas, dentre outras); iii) falta de ferramentas adequadas para a realização de suas atividades; iv) falta de automação nos processos; v) falta de coordenação, interação, cooperação, comunicação entre as partes envolvidas; vi) falta de participação do setor no processo de desenvolvimento e escolha de novos produtos; vii) falta de incentivo para a procura e identificação de ferramentas úteis pelas administrações a seus servidores; e, viii) isolamento do servidor atuante, sem a devida motivação para o trabalho em equipe e colaborativo.

Diante da necessidade de melhorias, para pôr em prática as ações voltadas para solucionar os problemas a serem abordados, o escopo de atuação proposto ao InfiscLab consiste de: i) instituir canal aberto a ideias voltadas para a transformação digital; ii) disseminar conhecimento, metodologias ágeis e ferramentas colaborativas; iii) coordenar os atores internos da empresa e convidados envolvidos com o problema/solução; iv) 
auxiliar no dimensionamento do problema/solução; v) elaborar projetos visando a captação de recursos; vi) desenvolver solução (produto, serviços e metodologia) em conjunto com os envolvidas, de forma colaborativa; vii) divulgar a solução no mercado; viii) avaliar a receptividade do mercado e retroagir adequadamente; ix) promover operação assistida da solução; $x$ ) disponibilizar capacitações em ambiente virtual (via plataforma de Ensino a Distância - EAD, por exemplo); e, xi) avaliar a satisfação do público-alvo com a solução disponibilizada e retroagir de forma adequada.

O canal para o trânsito das novas ideias ocorre em três frentes: i) iniciativa do setor público, neste caso dá-se através da comunicação por parte do representante do ente público; ii) iniciativa do setor privado, neste caso ocorre por rede de contatos junto ao mercado; e, iii) iniciativa da patrocinadora do InfiscLab, a partir de estudo de casos e de experiências obtidas.

\subsection{Serviços}

O InfiscLab proporciona os seguintes serviços, que são prestados na forma de:

i) Cursos - definido um tema específico, roteirizado, objetivando a melhoria de processos, abordando em maior nível de detalhamento do assunto aos participantes. Nos cursos são abordados técnicas, tecnologias, metodologias e processos, de maneira abrangente.

ii) Palestras/Webinários - abordando assuntos relacionados à demanda do cliente, demonstrando técnicas, melhorias e estudos relacionados aos segmentos de sua atuação. Através desse processo, apresenta-se aos participantes ideias inovadoras, novidades tecnológicas e métodos ágeis como Scrum [Shuterland 2016] e Design Thinking [Lewrick; Link; Leifer 2018].

iii) Oficinas - adotando uma abordagem técnica, com intensa participação do cliente, serão discutidas ideias, propostas e criação de metodologias de trabalho, processos, elaboração de casos de uso, dentre inúmeras dinâmicas, visando sempre a comunicação através de uma linguagem informal lúdica.

Com isso, o InfiscLab exerce um importante papel disseminador de conhecimento inclusive visando a: i) levar a transformação digital dos Municípios; ii) disseminar a cultura da criação dos laboratórios de estudos inovadores; iii) e ser agente colaborador de interlocução entre municípios e todos os demais segmentos da sociedade.

Tais serviços estão organizados e disponibilizados em página Web do InfiscLab, junto ao portal da empresa Infisc que sempre disponibilizará suporte auxiliar em todos os procedimentos técnicos e jurídicos que se fizerem necessários durante as etapas das demandas pelos parceiros internos e externos do laboratório.

\subsection{Estrutura}

O InfiscLab está subordinado às diretrizes da Diretoria da Infisc, contando com uma estrutura fixa mínima, e sua equipe é formada a partir da criação de projetos. Todas as decisões são tomadas de acordo com as diretrizes traçadas pela Diretoria, sendo escutados todos os parceiros internos e externos envolvidos no projeto, e para ela o InfiscLab deve reportar todas suas atividades. A Figura 1 mostra um organograma, ilustrando este posicionamento do InfiscLab na estrutura da Infisc. 


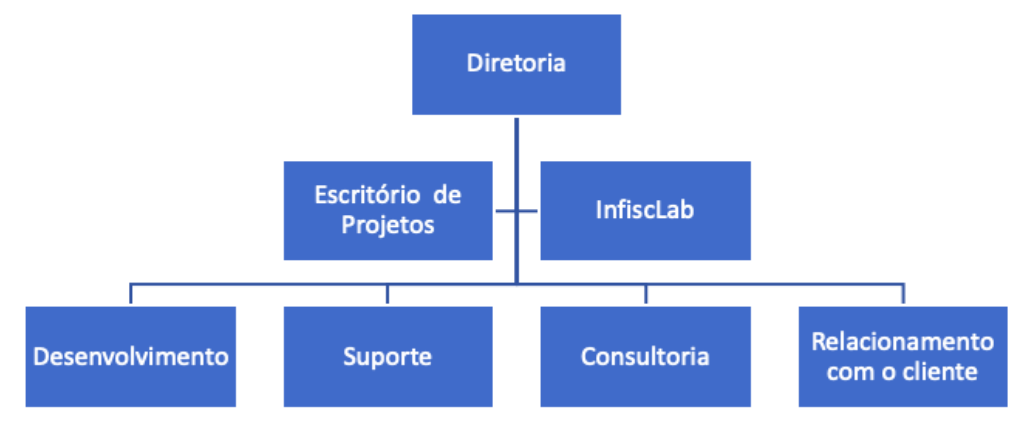

Figura 1. Organograma

Para materialização do InfiscLab, foram alocadas pessoas oriundas dos vários setores da empresa Infisc, formando-se uma equipe multidisciplinar, com a possibilidade de inclusão de pessoal externo para participação em projetos específicos, tais como, consultores especializados e técnicos.

\subsubsection{Pessoas}

A equipe inicial do InfiscLab, oriunda dos quadros da Infisc, é composta por profissionais de diferentes áreas de formação, desde economistas até desenvolvedores de software, com formações e experiências diversas.

A coordenação do InfiscLab está a cargo do Diretor de Pesquisa e Inovação da Infisc. Para tanto, conta com o apoio da equipe do Escritório de Projetos da Infisc que tem a coordenação do Diretor de Planejamento e Gestão (ver organograma mostrado na Figura 1). Este constitui o quadro de pessoal fixo, que conta com horas de trabalho alocadas para atividades no laboratório, de acordo com as demandas de projetos aprovados.

Para cada projeto a ser realizado no laboratório, são alocadas demais pessoas dos diversos setores da Infisc, a saber: das áreas de consultoria de conhecimento em Inteligência Fiscal, Captação de Recursos, Controle Orçamentário, bem como das áreas de Desenvolvimento de Sistemas, Suporte e Atendimento, Infraestrutura de TIC e da área comercial. Além dos colaboradores internos, a Agência de Comunicação, parceiros e partes interessadas no problema/solução são incorporados de acordo com a demanda do projeto.

Diante do foco de atuação do InfiscLab, importante na alocação de pessoas no laboratório, é a participação de pessoas convidadas oriundas das administrações fazendárias e tributárias dos municípios e eventualmente cidadãos, que porventura atuem em áreas de interesse do projeto a ser trabalhado e que sejam essenciais para o processo de desenvolvimento dos produtos no laboratório. A utilização do InfiscLab é aberta a todos os possíveis interessados em desenvolver algum produto inovador, bastando para isto estar associado a algum projeto que tenha sido submetido ao laboratório e tenha sido aprovado pela Diretoria.

\subsubsection{Recursos}

Na primeira fase da criação do InfiscLab, foi priorizada a realização de projetos que pudessem ser predominantemente conduzidos de forma não-presencial. Esta definição de foco em ambientes virtuais, se justifica principalmente com a experiência positiva obtida com a utilização das interações de forma remota, adotadas nestes tempos atuais de 
pandemia. A Figura 2 mostra o ambiente físico do InfiscLab, que dá suporte a esta estratégia baseada em atividades realizadas de forma não-presencial.

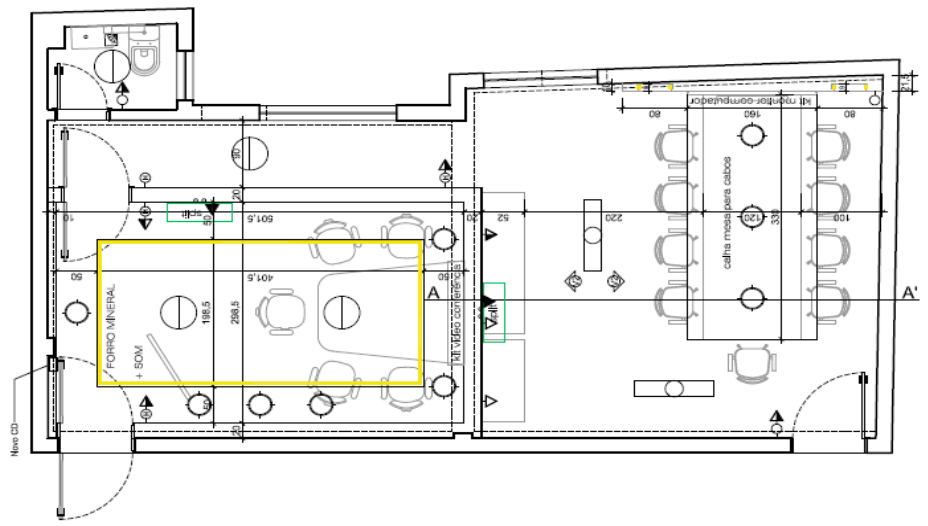

Figura 2. Planta baixa do ambiente físico do InfiscLab

Esta estratégia possibilita uma melhor logística organizacional para todos os parceiros do InfiscLab, especialmente através do aproveitamento da infraestrutura que a Infisc já possui para vídeo-conferências, tele-reuniões e transmissão de palestras, mostradas na planta baixa da Figura 2 e ilustradas pelos projetos 3D mostrados Figura 3 a seguir.

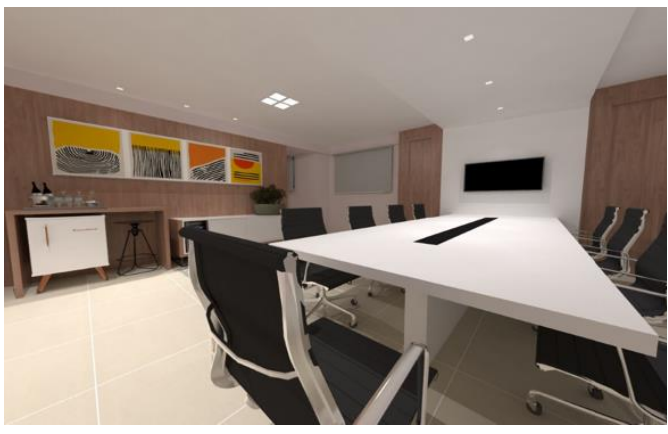

a)

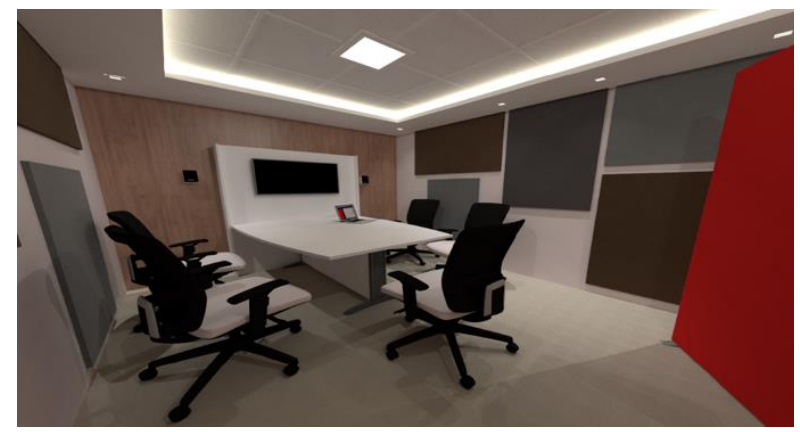

b)

Figura 3. Projeto 3D da sala de a) reuniões e de b) videoconferência do InfiscLab

Além deste espaço físico e recursos para comunicação eficiente, já disponíveis na Infisc para a implantação do laboratório, são alocados recursos computacionais, em ambiente na nuvem, para hospedagem das diferentes ferramentas tecnológicas, que serão utilizadas nas atividades a serem realizadas nos projetos.

Dentre as ferramentas utilizadas nos projetos do InfiscLab, destacam-se: o Figma (http://figma.com) e o Miro (http://miro.com) para criação colaborativa; o Redmine (http://redmine.org) para a gestão de projetos; o github (http://github.com) para repositório de informações; o Moodle (http://moodle.org) e o Google Classroom (http://classroom.google.com) para criação de ambientes de aprendizagem; o Discord (http://discord.com) e o Google Meet (http://meet.com) para ambientes de comunicação; além de outras ferramentas, que sejam demandadas por algum projeto em andamento no InfiscLab.

Os recursos financeiros são aportados para a realização das atividades dos projetos do InfiscLab, de acordo com avaliação da Diretoria levando em conta a relevância dos 
projetos submetidos e usando valores previstos em orçamento da Infisc para as atividades relacionadas com inovação.

Outra fonte de recursos financeiros são os parceiros externos da Infisc também interessados nos produtos a serem desenvolvidos. Além disso, a Infisc conta com profissional especializado na captação de recursos a partir de diferentes fontes, dependendo do tema do projeto a ser realizado.

\subsubsection{Parceiros}

Nos projetos realizados no InfiscLab, as parcerias são essenciais, pois é preciso estabelecer acordos de cooperação com os setores fazendários e tributários dos municípios, de maneira a viabilizar a participação deles nas atividades dentro do laboratório, durante o desenvolvimento dos produtos inovadores. A Figura 4 ilustra os parceiros que podem se envolver nos projetos realizados pelo InfiscLab.

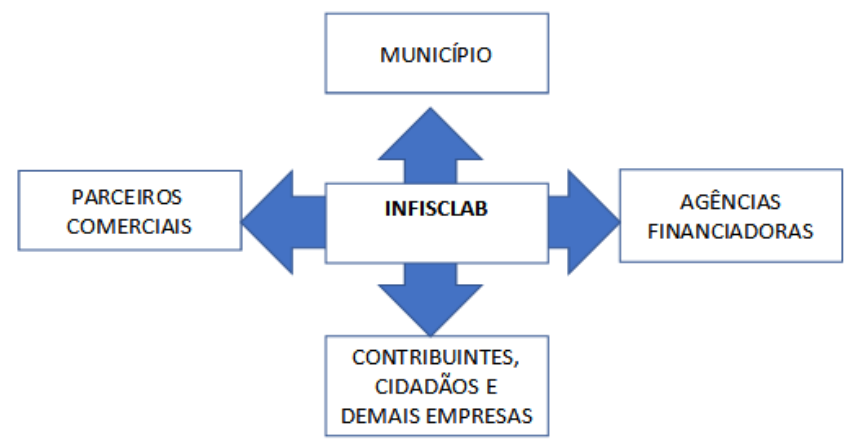

Figura 4. Rede de parceiros do InfiscLab

Outros parceiros em potencial do InfiscLab incluem contribuintes, cidadãos e empresas, bem como, agências financiadoras de projetos, assim como consultores e profissionais especializados no assunto do projeto. Para exemplificar a importância destas parcerias, pode-se citar o projeto-piloto que está sendo desenvolvido atualmente, que envolve o Imposto sobre a Transmissão Onerosa de Bens Imóveis (ITBI).

\subsection{Aprendizagem}

Como as atividades de desenvolvimento de produtos envolvem várias metodologias e tecnologias relativamente recentes, o InfiscLab tem promovido e continuará promovendo a realização de capacitações para habilitar toda a equipe da Infisc nas metodologias e ferramentas empregadas no laboratório, possibilitando a participação de todo o pessoal nas atividades do laboratório.

Estas mesmas capacitações estão sendo oferecidas para os clientes, bem como para os parceiros do InfiscLab, de maneira a tornar as atividades as mais eficazes possível. Essas capacitações permitem alinhar conhecimentos, métodos, formas de planejar e executar e ferramentas para potencializar o compartilhamento de ideias e pensamentos, entre todos os participantes de projetos no laboratório, visando identificar oportunidades relevantes para todos.

O InfiscLab atua a partir de uma metodologia própria construída a partir da experiência e análise de casos e da associação com experiências metodológicas conhecidas no mercado, a exemplo da utilização do Design Thinking [Leweick; Link; 
Leifer 2018]. O laboratório utiliza uma abordagem simples, com uso de ferramentas desenvolvidas pela Infisc ou disponíveis através de parceiros.

Todos os materiais produzidos, a partir das atividades nos projetos do laboratório, são armazenados e colocados à disposição de todos os participantes dos projetos e eventuais parceiros envolvidos.

\subsection{Comunicação}

O InfiscLab tem como um de seus objetivos propiciar uma maior comunicação com o setor público municipal. Através da coleta e compartilhamento de conteúdos, se busca disseminar a cultura da inovação voltada para a transformação digital do setor público municipal.

O laboratório tem proporcionado tanto aos seus colaboradores, como aos representantes do público-alvo (servidores municipais), a possibilidade de participar de experiências de aprendizagem por meio de oficinas de treinamento e de cursos no formato EAD. Tais experiências visam nivelar o conhecimento sobre os temas relacionados com problema sendo abordado e as metodologias a serem empregadas durante a realização dos trabalhos, permitindo uma maior e melhor interação entre os participantes do InfiscLab no desenvolvimento de soluções inovadoras.

\section{Estudo de Caso: ITBI}

Para validar o projeto, criação, instalação e operacionalização do InfiscLab foi escolhido, como caso-piloto, a produção de um projeto de uma solução para apoio às administrações fazendárias municipais na área do ITBI (como já mencionado anteriormente), que não possui ainda atualmente uma metodologia adequada para os procedimentos de avaliação dos imóveis na definição da base de cálculo do imposto.

Neste estudo de caso piloto, as interações têm por objetivo a obtenção de informações e sugestões, com os seguintes atores: i) colaboradores da Infisc com formação jurídica, contábil e especialização na área tributária, detentores de notório saber nessa área, inclusive, em relação ao Imposto sobre a Transmissão onerosa de Bens Imóveis (ITBI); ii) servidores municipais, detentores de cargo de Fiscal Tributário e detentores de cargos auxiliares na fiscalização tributária do ITBI; iii) corretores de imóveis, que atuam na área de intermediação imobiliária; iv) titulares e servidores de tabelionatos e de ofícios do registro de imóveis; v) profissionais da Infisc da área de TI, que serão os responsáveis pelo desenvolvimento dos sistemas computacionais e pelo atendimento de suporte técnico a ser dado aos usuários da solução ITBI Digital; vi) profissionais de áreas afins que possuem influência direta e indiretamente nos procedimentos; e, vii) empresa de comunicação contratada da Infisc que se encarregará da disseminação de conteúdos nos diversos canais de comunicação a serem utilizados pelo InfiscLab. A Figura 5 apresenta o fluxo de informações entre os envolvidos no estudo de caso sobre ITBI. 


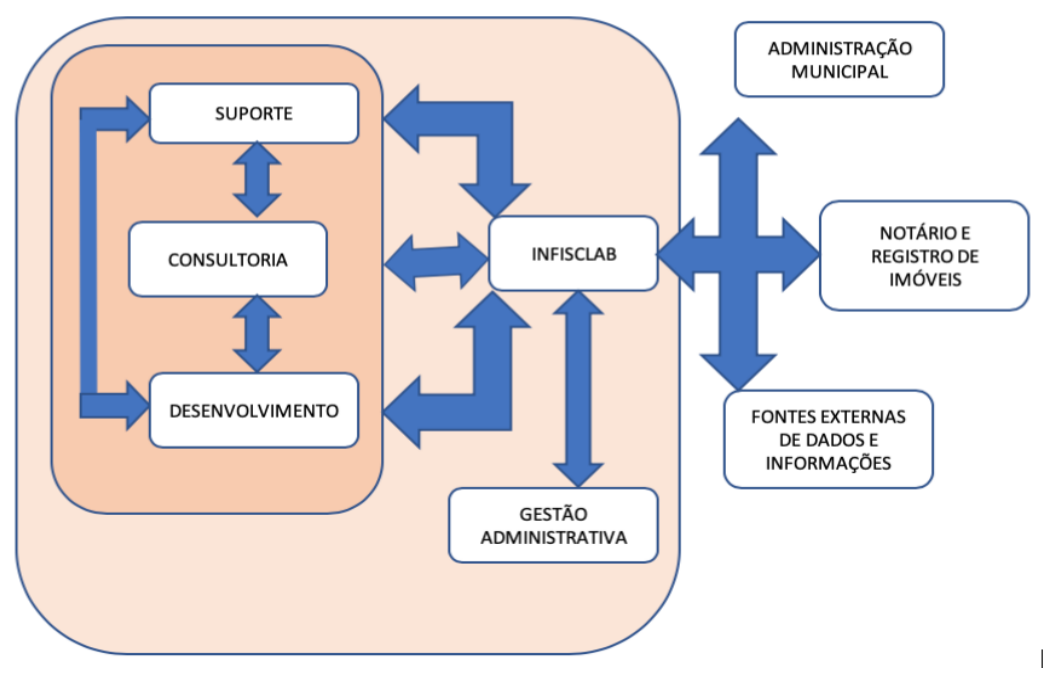

Figura 5. Fluxo de relacionamentos no estudo de caso sobre ITBI

Com estas interações, se está concretizando o ideal do modelo do InfiscLab, em que as pessoas, para as quais os produtos são voltados, são atores ativos em todas as etapas do processo de desenvolvimento dos produtos e serviços.

\subsection{Problemas do ITBI}

Justifica-se essa escolha por ser o ITBI um imposto da competência de arrecadação dos municípios brasileiros e do Distrito Federal, introduzido no direito brasileiro pela Constituição Federal de 1988. Até então, havia o "Imposto sobre a Transmissão, a Qualquer Título, de Bens Imóveis por Natureza e Acessão física, e de Direitos Reais sobre Imóveis, Exceto os de Garantia, bem como sobre Direitos à aquisição de Imóveis" (CF de 1967, art. 24, I), de competência estadual e do Distrito Federal, em que uma parcela de vinte por cento do valor arrecadado era entregue pelo Estado ao município onde estava localizado o bem.

A Constituição de 1988 desdobrou o imposto em dois:

- o "Imposto de Transmissão Causa Mortis e Doação, de Quaisquer Bens ou Direitos" (CF de art. 155, I), de competência estadual e do Distrito Federal, e

- o "Imposto de Transmissão 'Inter Vivos', a Qualquer Título, por Ato Oneroso, de Bens Imóveis, por Natureza ou Acessão Física, e de Direitos Reais sobre Imóveis, Exceto os de Garantia, bem como Cessão de Direitos a sua Aquisição" (CF de 1988, art. 156, II), de competência dos municípios e do Distrito Federal.

Frente a essa situação histórica identifica-se o problema: os municípios, em sua quase totalidade, simplesmente copiaram a forma que os estados adotavam para o procedimento administrativo de avaliação e cobrança do antigo imposto (vigente até 1988), sem qualquer adaptação, o que ainda perdura até os dias atuais. Importante ressaltar que essa situação, apesar de perdurar, não é adequada, pois o que está em uso não abrange as efetivas necessidades municipais.

Outro problema relevante que se tem conhecimento, é o empirismo adotado para os procedimentos de avaliação dos imóveis. Sabe-se que a Associação Brasileira de Normas Técnicas editou normativo para a avaliação de imóveis que, conforme contatos já havidos com alguns municípios, não costuma ser usado no processo de avaliação, sendo 
que muitos dos avaliadores municipais sequer conseguem entender o conteúdo daquele normativo. Assim, deve-se buscar o estabelecimento de uma metodologia que busque técnicas avaliativas, mas que também busque fontes de dados internos e externos que convalide os processos avaliativos. Entre essas fontes externas, tem-se o valor do CUBSinduscon, que divulga mensalmente os custos da construção civil (disponível em https://sinduscon-rs.com.br/produtos-e-servicos/pesquisas-e-indices/cub- rs).

\subsection{Abordagem adotada no InfiscLab}

Definido o problema, buscou-se a identificação de uma proposta para o primeiro projeto a ser estudado, desenvolvido e implementado pelo InfiscLab: estabelecer, como seu primeiro e piloto projeto, a criação de um sistema totalmente digital, que possa modernizar, racionalizar e simplificar os procedimentos administrativos para o controle da arrecadação do ITBI, mediante passagem por um laboratório de inovação Atualmente, o InfiscLab está interagindo com os diferentes envolvidos no processo do ITBI para definir como abordar cada um destes problemas em aberto, utilizando as metodologias ágeis adotadas no laboratório.

\subsection{Experiências a partir do estudo de caso sobre ITBI}

A partir da realização do estudo de caso sobre o ITBI, foi realizado um evento pelo InfiscLab na empresa Infisc sob o formato de maratona online (do termo em inglês, hackathon), que incluiu todos os colaboradores internos, organizados em grupos para construir descrições em linguagem simples, sem adição de termos técnicos ou jurídicos acessível a todos os demais parceiros internos e externos, de todos os produtos que a empresa oferece atualmente. O resultado alcançado obteve avaliação positiva de todos os participantes, e produziu uma documentação em linguagem simples que será de grande utilidade para todos os possíveis interessados em conhecer os produtos e serviços da Infisc.

\section{Conclusão}

A partir dessas experiências relatadas, a Infisc pode concluir que, efetivamente, a manutenção de um laboratório de inovação suprido dos adequados recursos operacionais, se transforma em um elemento apoiador da administração e capaz de incentivar a produção de ideias e seus desenvolvimentos mediante o uso de técnicas e ferramentas ágeis e apropriadas para cada projeto.

A instalação do laboratório a partir de implementação de projetos práticos, inicialmente mais simples, vem demonstrar sua utilidade e com os ganhos advindos dessas experiências, o uso de ferramentas adequadas e a troca de conhecimento com outros grupos similares e com entidades voltadas à implementação e divulgação de ações promotoras de inovação, se estará consolidando uma nova fase na empresa Infisc voltada à mudança para melhor, baseada em soluções inovadoras.

Somente o futuro poderá convalidar por inteiro o verdadeiro valor dessa ideia, mas, o certo, é que neste curto espaço de tempo de presença do InfiscLab já estão sendo obtidos resultados significativos na melhoria da gestão da empresa via seu laboratório de inovação. 


\section{Referências}

Nascimento, Francisco A. M.; Lehnen, F.; Moré, Morecy V.; Leizer, Salomão A. (2009) GIF: A Web-based System for Tax Management and Fiscal Intelligence in Municipal Tax Administration. In: 3rd International Conference on theory and practice of Electronic Governance (ICEGOV'09). ACM, New York/NY/USA, 127-133.

Cavalcante, Pedro et al. (2017) Inovação no setor público: teoria, tendências e casos no Brasil. Brasília: Enap: Ipea, 266 p.

Cavalcante, Pedro et al. (2019) Perfis e características das equipes e dos laboratórios de inovação no Brasil. In: P. Cavalcante (org.). Inovação e políticas públicas: superando o mito da ideia. Brasília: Ipea.

Conexão Inovação Pública RJ (2021) Dimensões de um laboratório de inovação. Disponível em <https://drive.google.com/drive/folders/1KpYj7vYHdLP3R7_ CoCTbrJqy1PsND2s8?usp=sharing > Acesso em 29/03/2021.

Cesul Lab (2021) Cesul Lab - Canal no Youtube. Disponível em <https://www.youtube.com/c/CesulLab/about> Acesso em 15/04/2021.

LeMay, Matt (2019) Agile for Everybody. Sebastopol/CA/USA: O’Reilly Media.

Leurs, Bas; Roberts, Isobel (2018) Playbook for innovation learning: 35 diagrams to support talking and thinking about learning for innovation. London: NESTA.

Lewrick, M., Link, P., Leifer, L. (2018). The Design Thinking Playbook: Mindful Digital Transformation of Teams, Products, Services, Businesses and Ecosystems. Reino Unido: Wiley.

Mulgan, Geoff (2014) The radical's dilemma: an overview of the practice and prospects of Social and Public Labs. UK: Nesta. (Version 1)

NauLab (2021) NauLab - Portal da Prefeitura de Blumenau/SC. Disponível em <https://www.blumenau.sc.gov.br/secretarias/gabinete-do-prefeito/gapref/prefeitura-desenvolve-o1ao-laborataorio-de-inovaacaao-do-setor-paoblico-de-blumenau22 > Acesso em 15/04/2021.

OCDE (2018) Oslo Manual: Guidelines for collecting, reporting and using data on innovation. Paris: OECD Publishing.

Sano, Hironobu (2020) Laboratórios de inovação no setor público: mapeamento e diagnóstico de experiências nacionais. Brasília: Enap.

Sutherland, J. (2016). Scrum: a arte de fazer o dobro do trabalho na metade do tempo. Brasil: Leya Brasil.

TCU (2021) coLAB-i: Laboratório de inovação do Tribunal de Contas da União. Disponível em <https://portal.tcu.gov.br/colab-i> Acesso em 15/03/2021. 